\title{
Impact of 2008 global economic crisis on suicide: time trend study in 54 countries
}

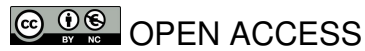

\author{
Shu-Sen Chang research assistant professor ${ }^{123}$, David Stuckler senior research leader ${ }^{45}$, Paul Yip \\ professor $^{16}$, David Gunnell professor ${ }^{2}$
}

${ }^{1}$ HKJC Centre for Suicide Research and Prevention, The University of Hong Kong, Hong Kong Jockey Club Building for Interdisciplinary Research, 5 Sassoon Road, Pokfulam, Hong Kong SAR, China; ${ }^{2}$ School of Social and Community Medicine, University of Bristol, Bristol, UK; ${ }^{3}$ Ju Shan Hospital, Taoyuan, Taiwan; ${ }^{4}$ Department of Sociology, University of Oxford, Oxford, UK; ${ }^{5}$ Department of Public Health and Policy, London School of Hygiene and Tropical Medicine, London. UK; ${ }^{6}$ Department of Social Work and Social Administration, University of Hong Kong, Hong Kong SAR, China

\begin{abstract}
Objective To investigate the impact of the 2008 global economic crisis on international trends in suicide and to identify sex/age groups and countries most affected.

Design Time trend analysis comparing the actual number of suicides in 2009 with the number that would be expected based on trends before the crisis (2000-07).
\end{abstract}

Setting Suicide data from 54 countries; for 53 data were available in the World Health Organization mortality database and for one (the United States) data came the CDC online database.

Population People aged 15 or above.

Main outcome measures Suicide rate and number of excess suicides in 2009.

Results There were an estimated 4884 (95\% confidence interval 3907 to 5860) excess suicides in 2009 compared with the number expected based on previous trends (2000-07). The increases in suicide mainly occurred in men in the 27 European and 18 American countries; the suicide rates were $4.2 \%$ (3.4\% to $5.1 \%$ ) and $6.4 \%$ (5.4\% to $7.5 \%)$ higher, respectively, in 2009 than expected if earlier trends had continued. For women, there was no change in European countries and the increase in the Americas was smaller than in men (2.3\%). Rises in European men were highest in those aged 15-24 (11.7\%), while in American countries men aged 45-64 showed the largest increase (5.2\%). Rises in national suicide rates in men seemed to be associated with the magnitude of increases in unemployment, particularly in countries with low levels of unemployment before the crisis (Spearman's $r_{s}=0.48$ ).

Conclusions After the 2008 economic crisis, rates of suicide increased in the European and American countries studied, particularly in men and in countries with higher levels of job loss.

\section{Introduction}

The 2008 economic crisis has had a far reaching impact on countries around the world. Turmoil in the banking sector led to downturns in stock markets, bankruptcies, housing repossessions, and rises in unemployment. The International Labour Organization estimated that the number of jobless worldwide reached about 212 million in 2009, an increase of 34 million compared with 2007. ${ }^{1}$ The World Health Organization has raised concern over the crisis' impact on global health and called for integrated multisectoral actions to closely monitor and protect health, in particular among poor and vulnerable people. $^{2}$

There is widespread concern that suicide rates might increase in countries affected by the global economic crisis, ${ }^{2}$ in view of evidence that economic downturns, and associated rises in unemployment, are followed by increases in suicide. ${ }^{3-10}$ For example, it is estimated that the 1997 economic crisis in Japan, South Korea, and Hong Kong resulted in over 10000 excess suicides. ${ }^{8}$ Previous research has found that economic downturns tend to have the greatest effects on men of working age; rises in suicide were larger in men than in women and in adults of working age than older people during the Russian economic crisis in the early $1990 \mathrm{~s}^{5}$ and the 1997 Asian economic crisis. ${ }^{8}$ Available studies of the impact on suicide of the 2008 global financial crisis reported data from only a limited number of countries ${ }^{11}$ or single countries. ${ }^{12-14}$ There has been no systematic investigation into the broader international pattern or the sex/age groups and regions most affected, although this information is urgently needed as there is a concern that governments' austerity measures might inadvertently lead to negative impact on 
population mental health and further increase suicide rates. ${ }^{15} \mathrm{~A}$ recent analysis of data from 10 European countries provided an early indication of the impact of the current economic crisis on suicide; all but one of these countries experienced more suicides in 2009 than in $2007 .{ }^{11}$ Three recent studies with data from single countries-England, ${ }^{12}$ Italy,${ }^{13}$ and the United

States $^{14}$ - found a significant rise in suicide during the 2008-10 recession. These analyses, however, were based on a limited number of countries and have yet to assess sex and age specific effects, the extent to which other countries have been affected or to quantify the overall "excess suicides" attributable to the economic crisis.

Using the latest available data on suicides from 27 European and 27 non-European countries, we assessed changes in suicide rates after the economic crisis in 2008 as well as differential effects by sex, age, country, and change in employment.

\section{Methods \\ Data series}

We identified 53 countries for which data on suicide in the WHO mortality database (the version released on 11 November 2012) ${ }^{16}$ were complete and valid for the period 2000-09 (fig $1 \Downarrow$ ). To investigate the impact of the global economic crisis, we considered changes in suicide rates in 2009 mainly because it is the first complete year after the crisis began in summer 2008. Four countries (Bahrain, Egypt, Saint Vincent and Grenadines, and South Africa) were excluded because of probable substantial miscoding of suicides, indicated by the low rates of certified suicide and high ratios of undetermined death to suicide..$^{17}$ The WHO database provides the most comprehensive standardised national mortality statistics for countries around the world. ${ }^{19}$ Complete suicide data in 2000-09 for the US (where the 2008 global economic crisis began) were unavailable in the database at the time of the study and were therefore extracted from the online database of the Centers for Disease Control and Prevention. ${ }^{20}$ These 54 study countries included 27 European countries, 18 American countries, eight Asian countries, and one African country. Figure $2 \Downarrow$ shows a map of the study countries and their suicide rates in 2009. The 27 European countries included $78 \%$ of Europe's population, and the 18 American countries accounted for $88 \%$ of the population in the Americas. ${ }^{21}$ In contrast, the Asian and African countries included in the study accounted for only $5 \%$ and $0.1 \%$ of the population in these two continents. Of the 54 study countries, data for 2010 were also available for 29 countries, including 20 European countries ( $46 \%$ of Europe's population) and nine non-European countries (fig $1 \Downarrow$ ).

We used ICD (international classification of diseases) codes to extract suicide data (ninth revision (ICD-9) codes E950-E959, 10th revision (ICD-10) codes X60-X84). Data for events of undetermined intent (ICD-9 E980-E989 and ICD-10 Y10-Y34) were also extracted as previous studies indicated that in some countries a considerable proportion of deaths in this category are probably suicide ${ }^{17}$; ; data for these deaths were included in a sensitivity analysis to investigate the possible impact of misclassification of suicide. Coding for suicide was almost the same in the two ICD revisions, and previous analyses found no impact on the total number of suicide deaths between the two revisions. ${ }^{22}$ Eight countries (Austria, Bulgaria, Cuba, Guatemala, Hong Kong SAR, Kazakhstan, Ireland, and Mauritius) used both ICD-9 and ICD-10 over the study period, but none of these changes in ICD versions occurred around the time of the 2008 economic crisis; all other countries used either ICD-9 or ICD-10 alone throughout the study period.
Population data from 19 countries were incomplete in the WHO database and were obtained from the United Nations population database. ${ }^{21}$ Annual sex specific age standardised suicide rates for people aged 15 or above were calculated in each country by using the WHO world standard population. ${ }^{23}$

We extracted data for unemployment and gross domestic product (GDP) per capita from the International Monetary Fund's world economic outlook database. ${ }^{24}$ Unemployment was used as the main economic indicator as previous research showed that changes in unemployment were more closely related to short term effects on mortality than other economic indicators, ${ }^{25}$ and its rise might have accounted for some of the increases in suicide during previous recessions. ${ }^{89}$

\section{Statistical analysis}

To calculate changes in trends in suicide rates and excess suicides related to the global economic crisis requires assessment of time trends and estimation of the expected number of suicides (that is, what would have happened if the economic crisis had not occurred) and then quantification of deviation from these trends.

In the first step of the analysis, we chose the year 2000 as the starting point for estimating trends in suicide before the crisis because rates in some countries in the 1990s were influenced by the recession in the early $1990 \mathrm{~s}^{5626}$ and the Asian economic crisis in the late 1990s. ${ }^{8}$ Furthermore, over long time periods population suicide rates can be influenced by factors such as the changing availability of highly lethal methods of suicide and improved detection and treatment of psychiatric disorders. ${ }^{27}$ The main analysis focused on suicide rates in 2009, and results for 2008 and 2010 are shown in appendix 1; a previous analysis indicated that some European countries already showed some rises in suicide in 2008 compared with $2007 .{ }^{11}$

We used negative binomial regression models to estimate suicide trend in each country between 2000 and 2007. Linear trends were estimated by including the calendar year in the models; a similar approach was used in a recent paper to estimate excess suicides during recessions in England. ${ }^{12}$ Negative binomial regression is Poisson regression with an additional Gamma distributed parameter to adjust for overdispersion (extra-Poisson variation); a likelihood ratio test was used to examine overdispersion by comparing the data fits of Poisson and negative binomial models. ${ }^{28}$ As there was evidence for overdispersion in Poisson models in 21 countries, we use negative binomial models throughout. We estimated models for men and women separately because of previously documented sex differences in the association between economic changes and suicide. ${ }^{56829} \mathrm{We}$ included age group (15 categories (nine categories for the US data) starting from age 15-19 up to age $\geq 85$ ) and an offset term " $\log$ (population per year and age group)" to adjust for annual changes in population figures and age structure. Based on these models we estimated the expected sex and age specific numbers of suicides in 2008, 2009, and 2010 in each country, given the pre-2008 trends. Models for men and women in different age groups - that is, aged 15-24 (just entering labour market), 25-44 (early years of employment), 45-64 (later employment), and $\geq 65$ (after retirement)-were also estimated separately to investigate whether the impact of the global economic crisis varied among different subgroups. ${ }^{58}$ In the second step of the analysis, to investigate whether suicide rates in 2008, 2009, and 2010 were in line with year on year trends in 2000-07, we calculated excess suicides in 2008, 2009, and 2010 - that is, the differences between the actual number of suicides and that expected given the trends before the crisis. 
We used the standard errors of the expected number of suicides to estimate the $95 \%$ confidence intervals of excess suicides, reflecting the uncertainty in the estimated continuation of past trends. Rate ratios for suicide between the actual and the expected data were also calculated. Overall excess suicides and rate ratios across study countries were calculated by pooling data from individual countries. These were also estimated for European, American, and other countries separately, as well as separately for groups of countries of different continents, to investigate whether the crisis' impact varied in different regions. Within European countries we made a distinction between old (pre-2004) and new (post-2004) European Union (EU) member states and non-EU countries as they had different levels of GDP per capita. For the same reason we grouped American countries as North, Caribbean and Central, and South American countries and Asian countries as East Asian and other Asian countries, based on the United Nations' classification. ${ }^{30}$

To examine whether suicide rates rose more in countries with worse economic downturns, we used Spearman's correlation coefficients to investigate the association between suicide rate ratios in 2009 and percentage point changes in unemployment rates between 2007 (the baseline year) and 2009 (unemployment rates (in \%) in 2009 minus unemployment rates (in \%) in 2007) across study countries. We also conducted analyses stratified by unemployment level before the crisis (2007), as countries with low baseline unemployment rates and large rises in unemployment during the crisis might show the greatest rises in suicide rates. ${ }^{9}$ We used the median of unemployment rates across the 50 countries with available data in 2007 as the cut-off point.

All analyses in this study were conducted with Stata version 12 (StataCorp, College Station, TX, 2011), with two tailed tests used throughout.

\section{Results}

\section{Economic indicators}

Figure 3 shows overall changes in unemployment rates and GDP per capita across the 54 study countries, weighted by population size, in 2000-10, with year 2007 as reference. $\downarrow$ There was a reverse of previous falls in unemployment and a levelling off of rises in GDP in 2008, followed by $37 \%$ rises in unemployment and 3\% falls in GDP per capita in 2009, reflecting the onset of the global economic crisis in 2008. Figure 4 shows trends in unemployment in nine different groups of countries. $\Downarrow$ Within Europe all three groups of countries experienced rises in unemployment in 2009 (of between 17\% and $35 \%$ ) and 2010 (25\% to $36 \%$ ). Unemployment rates started rising in North American countries in 2008 (23\%), followed by dramatic increases in 2009-10 (94\% and 101\%). Caribbean and Central American countries also showed $40 \%$ to $45 \%$ rises in unemployment in 2009-10, while there was no increase in South American countries. East Asian countries experienced rises in unemployment of 26-27\% in 2009-10. Data from other Asian countries and one African country (Mauritius) showed no increases in unemployment in 2008-10 compared with 2007.

\section{Changes in suicide trends and excess suicides}

Table $1 \Downarrow$ shows rate ratios and excess suicides in 2009 , relative to those expected given the 2000-07 trends across 54 study countries. The rate ratio of 1.033 (95\% confidence interval 1.027 to 1.039$)$ indicates that overall suicide rate in men rose $3.3 \%$ (2.7\% to $3.9 \%$; (table 1), with an excess of 5124 (4219 to 6029) suicides. In contrast, there was no evidence for a change in rates in women $(-0.5 \%,-1.3 \%$ to $0.3 \%)$. When we combined data for men (5124 excess suicides) and women ( 240 fewer suicides) there were an estimated 4884 (3907 to 5860 excess suicides in 2009. In men, there seemed to be a graded diminution of increases in suicide with increases in age: 5.8\% (3.5\% to $8.1 \%$ ), $4.1 \%$ (2.3\% to $6.0 \%$ ), $3.6 \%$ ( $0.8 \%$ to $6.5 \%$ ) in those aged $15-24$, $25-44$, and $45-64$, respectively, and no change $(-2.3 \%,-6.4$ to $2.2 \%$ ) in those aged $\geq 65$.

Rises in suicide rates in men in 2009 were mainly seen in the 27 European countries $(4.2 \%, 95 \%$ confidence interval $3.4 \%$ to $5.1 \% ; 2937$ ( 2400 to 3475 ) excess suicides) and the 18 American countries $(6.4 \%, 5.4 \%$ to $7.5 \% ; 3175$ (2692 to 3658 ) excess suicides). There was also a small rise in suicide rates in women in American countries $(2.3 \%, 1.1 \%$ to $3.5 \%)$; in contrast there was no increase in European women. European men aged 15-24 had the greatest increases in suicide rates $(11.7 \%, 7.2 \%$ to $16.6 \%)$ in all age groups, while in American countries men aged 45-64 showed the greatest increase $(5.2 \%, 3.1 \%$ to $7.3 \%)$.

There was no strong evidence for a change in suicide rates in men or women in 2008 compared with previous trends when we combined data for all 54 countries (table A in appendix 1). Data for the 27 European countries showed a small decrease in suicide rates in men $(-0.9 \%, 95 \%$ confidence interval $-1.6 \%$ to $-0.2 \%$ ) but no change in rates in women, while rates increased $4.8 \%$ (3.9\% to $5.7 \%$ ) and $2.6 \%$ (1.5\% to $3.7 \%$ ) in men and women, respectively, in the 18 American countries and decreased $6.7 \%(5.4 \%$ to $7.9 \%)$ and $4.4 \%(2.7 \%$ to $6.0 \%)$, respectively, in the nine non-European/non-American countries. Available data for 2010 from 20 European countries showed a $10.8 \%$ (95\% confidence interval $10.1 \%$ to $11.6 \%$ ) rise in suicide in men and a $4.8 \%$ (3.8\% to $5.8 \%$ ) rise in suicide in women, with the largest proportional increase shown in men aged 15-24 (table B in appendix 1). In contrast, rates in men and women decreased by $6.2 \%$ (5.0\% to $7.3 \%$ ) and $8.3 \%$ (6.7\% to $10.0 \%)$, respectively, in nine non-European countries.

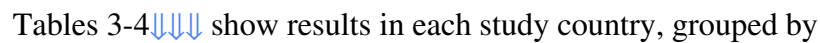
region in 2009. Within Europe, new EU member states, as a group, showed the largest increase in suicide rates in men (13.3\%) versus a $6.4 \%$ increase in old EU member states and no change in non-EU European countries (table 2) $\Downarrow$. Among American countries, Northern American countries and Caribbean and Central American countries showed $8.9 \%$ and $6.4 \%$ increases, respectively, versus a smaller increase (1.3\%) in South American countries (table $3 \Downarrow$ ). In women, only new EU member states experienced an increase in suicide $(7.7 \%)$ within Europe; Northern American and Caribbean and Central American countries showed an increase (2.3\% and $25.4 \%$, respectively) among American countries, while non-EU European countries and Southern American countries showed some reductions $(-2.7 \%$ and $-5.8 \%)$. Out of 27 European countries, 24 showed an increase in suicide rates in men $(\mathrm{P}<0.05)$, with Poland showing the largest absolute number of excess suicides (763, 95\% confidence interval 677 to 849). Among American countries, men in the US showed the largest number of excess suicides $(2309,1850$ to 2767). Appendix 2 shows age standardised suicide rates for men and women in each country in 2000-09, as well as the fitted linear trends based on data for 2000-07. Tables C and D in appendix 1 show results by country in 2008 and 2010, respectively.

There was some evidence for an association between the increases in suicide after the crisis and the increases in unemployment across study countries, particularly in men and in countries where the unemployment level before the crisis (2007) was relatively low (table $5 \Downarrow$ ). Spearman's correlation 
coefficients between suicide rate ratios in 2009 and percentage point changes in unemployment rates between 2007 and 2009 were $0.25(\mathrm{P}=0.075)$ in men and $0.10(\mathrm{P}=0.49)$ in women. In men, the correlation coefficient was $0.48(\mathrm{P}=0.016)$ in men countries with relatively low unemployment levels $(<6.2 \%)$ before the crisis and $0.31(\mathrm{P}=0.13)$ in countries with high unemployment levels $(\geq 6.2 \%)$ before the crisis.

\section{Sensitivity analysis}

The results were similar when we excluded six small countries (population aged $\geq 15<500$ 000; Aruba, Belize, Iceland, Luxembourg, Malta, and Suriname) that showed relatively unstable trends. Data for certified suicides and undetermined deaths combined showed similar findings (table $\mathrm{E}$ in appendix 1). When we used data for 2000-06 to estimate trends before the crisis, the pattern of rises in suicide in 2009 was similar (table $\mathrm{F}$ in appendix 1).

\section{Discussion}

We found a clear rise in suicide after the 2008 global economic crisis; there were about 4900 excess suicides in the year 2009 alone compared with those expected based on previous trends (2000-07). There were important differences in men and women as well as in the age pattern in different groups of countries. The increases were mainly in men from the 27 European countries and 18 American countries studied. All age suicide rates in European and American men were, respectively, 4.2\% and $6.4 \%$ higher in 2009 than expected if past trends had continued. In contrast there was no change in European women and a relatively smaller $(2.3 \%)$ increase in American women. In European countries, the impact has been felt most strongly by men aged 15-24, while men aged 45-64 were most affected in American countries. Rises in national suicide rates in 2009 seemed to be associated with the magnitude of increases in unemployment, particularly for men and in countries with low unemployment levels before the crisis. Our finding is likely to be an underestimate of the true global impact of the economic crisis on suicide as some affected countries, such as Australia and Italy, were not included. The rise in the number of suicides is only a small part of the emotional distress caused by the economic downturn. Non-fatal suicide attempts could be 40 times more common than completed suicides, ${ }^{31}$ and for every suicide attempt about 10 people experience suicidal thoughts. ${ }^{32}$

\section{Strengths and limitations}

This study is the first systematic investigation of the impact of the 2008 global economic crisis on international trends in suicide and the demographic groups/regions most affected. There are several limitations to our analysis. Firstly, this study is an observational analysis based on aggregate data. As we are explicitly considering the impact of the economic crisis on national suicide rates we considered the ecological design to be the most appropriate. While events other than the economic crisis could have influenced suicide trends in individual countries, it is unlikely that all study countries were affected at the same time as the crisis by different specific events given the magnitude of increases in suicide across study countries.

Secondly, data on suicides during the relevant period were not available for some large economies severely affected by the economic crisis. Other countries with a large population-such as China and India - were not included because of unavailability of data, but their economies were less affected by the economic crisis (GDP growth $9.2 \%$ and $6.6 \%$ in 2009 , respectively). ${ }^{24}$ The Asian countries and one African country (Mauritius) included in the study are not representative of all Asian and African countries. Most of the European and American population, however, were included. Thirdly, as the global economic crisis hit different countries at different times, monthly or quarterly data might show more detailed patterns of changes in trends in suicide than the annual data used in our study; such detailed data, however, were unavailable in the WHO mortality database. The study was also limited by data lags. Data for more additional years after the economic crisis, such as 2010 or later, might better show the trajectory of the impact, but they would not change the results for the years 2008-09 as presented in this study. Fourthly, variations in level of misclassification of suicide could lead to potential bias between countries. ${ }^{33}$ Our analysis focused on variations within countries, however, which adjusts for such varying surveillance. Furthermore, poor quality of data from single countries over time will lead only to non-differential misclassification of the outcome and so attenuate estimates of recession effects. Our sensitivity analysis based on certified suicides and undetermined deaths combined also showed similar findings.

\section{Comparison with previous findings}

Several lines of evidence suggest a causal role of the 2008 global economic crisis on subsequent rises in suicide in affected countries. Several recent studies have shown an increased prevalence of depression or anxiety after the economic crisis in Hong Kong, ${ }^{34}$ south Australia, ${ }^{35}$ Greece, ${ }^{36}$ England,${ }^{37}$ and Spain. ${ }^{38}$ Such deterioration in mental health was particularly seen in people who experienced unstable employment or financial problems. ${ }^{34} 3538$ Our finding is consistent with the documented increases in suicide during past recessions, such as the Great Depression in the $1930 \mathrm{~s},{ }^{347}$ the Russian crisis in the early $1990 \mathrm{~s},{ }^{56}$ and the Asian economic crisis in the late 1990s. ${ }^{8}$ Our data showed an association between the magnitude of rises in unemployment and increases in suicide in men, suggesting a dose-response effect. Several countries showed a downward trend in suicide before the 2008 economic crisis, particularly in men, and such trends were reversed afterwards (appendix 2), suggesting the impact of the crisis.

Our estimate of excess suicides (about 5000 in the year 2009) is lower than the 10000 excess suicides in 1998 proposed in the study of the Asian economic crisis. ${ }^{8}$ This is in part because of the different nature of the economic shock and our focus in this study on estimating excess suicides across all countries (several of which have not been affected), whereas the analysis of Asian data focused solely on the three affected countries.

Our finding of a greater increase in suicide in men than in women is consistent with increases seen during the Russian crisis ${ }^{5}$ and the Asian economic crisis. ${ }^{8}$ Recent studies of risks of depression in $\mathrm{Spain}^{38}$ and the $\mathrm{UK}^{37}$ corroborate our observations that men have greater mental health risks in the context of economic recession. Men are more likely to be the main earner in the family and thus more affected by the recession than women; they might experience a greater degree of shame in the face of unemployment and are less likely to seek help. The current crisis, however, tended to affect younger European men in contrast with the previous recessions, ${ }^{58}$ possibly attributable to the proportionally larger increases in unemployment in this group than other age groups since 2008. ${ }^{39}$ The causes of the greater impact on middle aged men than other age groups in American countries are less clear and need further investigation. $^{40}$

There are considerable variations in the effect of the crisis on risk of suicide across countries. Such variations probably relate 
to the severity of the recession as well as to varying social support and labour market protections in different countries. ${ }^{91} 42$ In parallel to our findings, previous research has shown a strong association between changes in unemployment rates and suicide rates. ${ }^{9} 102943$ Observational studies indicate that unemployed people have two to three times increased risk of suicide. ${ }^{29}$ Consistent with previous findings ${ }^{44}{ }^{45}$ we found stronger associations between increases in national suicide rates and unemployment rates in countries with low baseline unemployment rates than in countries with high unemployment rates. Acute economic downturns and rises in unemployment could lead to greater fear and anxiety in countries with lower baseline rates and thus greater increases in risk of suicide. ${ }^{9}$ Another possibility is a social density effect-if many people are already unemployed at baseline, the stigma of unemployment could be less and the impact of recession smaller.

\section{Implications}

Our findings show that economic crises pose considerable suicide risks; though previous studies suggest that these risks are not inevitable. Research has shown that active labour market programmes can help to offset the impact of economic recession on suicide, ${ }^{9}$ as successful re-employment has been found to substantially reduce, and in some cases eliminate, mental health risks of job loss. At a time of state retrenchment, countries with limited resources might usefully target labour market support at young and working age men. In many countries, however, government austerity is resulting in further job losses, posing additional suicide risks. Urgent action is needed to prevent the economic crisis leading to further increases in suicides.

Contributors: DG and S-SC had the idea for the study and designed the study with input from DS and PSFY. S-SC was responsible for obtaining data and statistical analysis, with input from PSFY. S-SC, DG, and DS led interpretation of the findings with additional input from PSFY. S-SC wrote the first draft, with input from DG and DS, and all authors contributed to successive drafts. S-SC is guarantor. All authors had full access to all of the data (including statistical reports and tables) in the study and can take responsibility for the integrity of the data and the accuracy of the data analysis.

Funding: This research received no specific grant from any funding agency in the public, commercial, or not-for-profit sectors. S-SC is supported by the Hong Kong Research Grants Council (RCG) general research fund (grants HKU784210M and HKU784012M) and a grant from the University of Hong Kong (Project Code 201203159017). DS is funded by a European Research Council investigator award. DG is a UK National Institute for Health Research senior investigator. The funders had no role in study design, data collection and analysis, decision to publish, or preparation of the manuscript.

Competing interest: All authors have completed the ICMJE uniform disclosure form at www.icmje.org/coi_disclosure.pdf (available on request from the corresponding author) and declare: no support from any organisation for the submitted work; no financial relationships with any organisations that might have an interest in the submitted work in the previous three years; no other relationships or activities that could appear to have influenced the submitted work.

Ethical approval: Not required.

Data sharing: No additional data available.

International Labour Organization. ILO global employment trends 2010-unemploymen reaches highest level on record in 2009. www.ilo.org/manila/info/public/pr/WCMS_124768/ lang--en/index.htm.

2 World Health Organization. Financial crisis and global health: report of a high-level consultation. WHO, 2009.

Swinscow D. Some suicide statistics. BMJ 1951;1:1417-23.

4 Morrell S, Taylor R, Quine S, Kerr C. Suicide and unemployment in Australia 1907-1990. Soc Sci Med 1993;36:749-56.
5 Gavrilova NS, Semyonova VG, Evdokushkina GN, Gavrilov LA. The response of violent mortality to economic crisis in Russia. Popul Res Policy Rev 2000;19:397-419.

6 Brainerd E. Economic reform and mortality in the former Soviet Union: a study of the suicide epidemic in the 1990s. Eur Econ Rev 2001;45:1007-19.

7 Tapia Granados JA, Diez Roux AV. Life and death during the Great Depression. Proc Natl Acad Sci U S A 2009;106:17290-5.

8 Chang SS, Gunnell D, Sterne JAC, Lu TH, Cheng ATA. Was the economic crisis 1997-1998 responsible for rising suicide rates in East/Southeast Asia? A time-trend analysis for Japan, Hong Kong, South Korea, Taiwan, Singapore and Thailand. Soc Sci Med 2009;68:1322-31.

9 Stuckler D, Basu S, Suhrcke M, Coutts A, McKee M. The public health effect of economic crises and alternative policy responses in Europe: an empirical analysis. Lancet 2009;374:315-23.

10 Luo F, Florence C, Quispe-Agnoli M, Ouyang L, Crosby A. Impact of business cycles on US suicide rates, 1928-2007. Am J Public Health 2011;101:1139-46.

11 Stuckler D, Basu S, Suhrcke M, Coutts A, McKee M. Effects of the 2008 recession on health: a first look at European data. Lancet 2011;378:124-5.

12 Barr B, Taylor-Robinson D, Scott-Samuel A, McKee M, Stuckler D. Suicides associated with the 2008-10 economic recession in England: time trend analysis. BMJ 2012;345:e5142

13 De Vogli R, Marmot M, Stuckler D. Excess suicides and attempted suicides in Italy attributable to the great recession. J Epidemiol Community Health 2013;67:378-9.

14 Reeves A, Stuckler D, McKee M, Gunnell D, Chang S-S, Basu S. Increase in state suicide rates in the USA during economic recession. Lancet 2012;380:1813-4.

15 Karanikolos M, Mladovsky P, Cylus J, Thomson S, Basu S, Stuckler D, et al. Financial crisis, austerity, and health in Europe. Lancet 2013;381:1323-31.

16 World Health Organization Statistical Information System. WHO mortality database. www. who.int/healthinfo/statistics/mortality_rawdata/en/index.html.

17 Ohberg A, Lonnqvist J. Suicides hidden among undetermined deaths. Acta Psychiatr Scand 1998;98:214-8.

18 Linsley KR, Schapira K, Kelly TP. Open verdict v. suicide-importance to research. Br J Psychiatry 2001;178:465-8

19 Varnik P. Suicide in the world. Int J Environ Res Public Health 2012:9:760-71.

20 Centers for Disease Control and Prevention. CDC WONDER online database. Compiled from compressed mortality file 1999-2009. http://wonder.cdc.gov/cmf-icd10.html.

21 United Nations Population Division. World population prospects, the 2010 revision. http: //esa.un.org/wpp/Excel-Data/population.htm.

22 Brock A, Griffiths C. Trends in suicide by method in England and Wales, 1979-2001. Health Stat Q 2003:20:7-17.

23 Ahmad O, Boschi-Pinto C, Lopez AD, Murray CJL, Lozano R, Inoue M. Age standardization of rates: a new WHO standard. WHO, 2000

24 International Monetary Fund. World economic outlook database. April 2012. www.imf.org/ external/pubs/ft/weo/2012/01/weodata/index.aspx.

25 Tapia Granados JA. Increasing mortality during the expansions of the US economy, 1900-1996. Int J Epidemiol 2005:34:1194-202.

26 Rancans E, Salander Renberg E, Jacobsson L. Major demographic, social and economic factors associated to suicide rates in Latvia 1980-98. Acta Psychiatr Scand 2001;103:275-81.

27 Gunnell D, Middleton N, Whitley E, Dorling D, Frankel S. Why are suicide rates rising in young men but falling in the elderly? A time-series analysis of trends in England and Wales 1950-1998. Soc Sci Med 2003:57:595-611.

28 Martuzzi M, Hills M. Estimating the degree of heterogeneity between event rates using likelihood. Am J Epidemiol 1995;141:369-74.

29 Platt S, Hawton K. Suicidal behaviour and the labour market. In: Hawton K, van Heeringen $\mathrm{K}$, eds. The international handbook of suicide and attempted suicide. John Wiley, 2000:309-84.

30 United Nations. Composition of macro geographical (continental) regions, geographical sub-regions, and selected economic and other groupings (revised 20 September 2011). http://millenniumindicators.un.org/unsd/methods/m49/m49regin.htm.

31 Schmidtke A, Bille-Brahe U, DeLeo D, Kerkhof A, Bjerke T, Crepet P, et al. Attempted suicide in Europe: rates, trends and sociodemographic characteristics of suicide attempters during the period 1989-1992. Results of the WHO/EURO Multicentre Study on Parasuicide. Acta Psychiatr Scand 1996:93:327-38.

32 Borges G, Nock MK, Haro Abad JM, Hwang I, Sampson NA, Alonso J, et al. Twelve-month prevalence of and risk factors for suicide attempts in the World Health Organization World Mental Health Surveys. J Clin Psychiatry 2010;71:1617-28

33 Kapusta ND, Tran US, Rockett IR, De Leo D, Naylor CP, Niederkrotenthaler T, et al. Declining autopsy rates and suicide misclassification: a cross-national analysis of 35 countries. Arch Gen Psychiatry 2011:68:1050-7.

34 Lee S, Guo WJ, Tsang A, et al. Evidence for the 2008 economic crisis exacerbating depression in Hong Kong. J Affect Disord 2010;126:125-33.

35 Shi Z, Taylor AW, Goldney R, Winefield H, Gill TK, Tuckerman J, et al. The use of a surveillance system to measure changes in mental health in Australian adults during the global financial crisis. Int J Public Health 2011;56:367-72.

36 Economou M, Madianos M, Peppou LE, Patelakis A, Stefanis CN. Major depression in the era of economic crisis: a replication of a cross-sectional study across Greece. J Affect Disord 2012;145:3018-14.

37 Katikireddi SV, Niedzwiedz CL, Popham F. Trends in population mental health before and after the 2008 recession: a repeat cross-sectional analysis of the 1991-2010 Health Surveys of England. BMJ Open 2012;2:e001790.

38 Gill M, Roca M, Basu S, McKee M, Stuckler D. The mental health risks of economic crisis in Spain: evidence from primary care centres, 2006 and 2010. Eur J Public Health 2013;23:103-8.

39 Eurostat European Comission. Unemployment statistics. http://epp.eurostat.ec.europa. eu/statistics_explained/index.php/Unemployment_statistics\#Male_and_female_ unemployment trends.

40 Centers for Disease Control and Prevention. Suicide among adults aged 35-64 years-United States, 1999-2010. Morbidity Mortality Weekly Report 2013:62:321-5.

41 Zimmerman SL. States' spending for public welfare and their suicide rates, 1960 to 1995 what is the problem? J Nerv Ment Dis 2002;190:349-60

42 Stuckler D, Basu S, McKee M. Budget crises, health, and social welfare programmes. BMJ 2010;340:c3311.

43 Chang SS, Sterne JA, Huang WC, Chuang HL, Gunnell D. Association of secular trends in unemployment with suicide in Taiwan, 1959-2007: a -series analysis. Public Health 2010;124:49-54 


\section{What is already known on this topic}

Research with data from a few mainly European countries indicated an increase in suicide rates after the 2008 global financial crisis It is unknown whether similar rises have occurred in other countries affected by the crisis and which sex/age groups are most affected

\section{What this study adds}

There have been increases in suicide rates after the 2008 economic crisis in the European and American countries studied

Rises in suicide have mainly occurred among men and in countries with higher levels of job loss. In Europe, men aged 15-24 have been particularly affected

44 Crawford MJ, Kuforiii B, Ghosh P. The impact of social context on socio-demographic risk factors for suicide: a synthesis of data from case-control studies. J Epidemiol Community Health 2010;64:530-4.

45 Maki N, Martikainen P. A register-based study on excess suicide mortality among unemployed men and women during different levels of unemployment in Finland. $J$ Epidemiol Community Health 2012;66:302-7.

Accepted: 12 August 2013

\section{Cite this as: BMJ 2013;347:f5239}

This is an Open Access article distributed in accordance with the Creative Commons Attribution Non Commercial (CC BY-NC 3.0) license, which permits others to distribute, remix, adapt, build upon this work non-commercially, and license their derivative works on different terms, provided the original work is properly cited and the use is non-commercial. See: http://creativecommons.org/licenses/by-nc/3.0/. 


\section{Tables}

Table 1| Rate ratios and excess suicides in 2009 relative to those expected based on trend 2000-07 in 54 countries* after world financial crisis in 2008

\begin{tabular}{|c|c|c|c|}
\hline & Rate ratio $(95 \% \mathrm{Cl})$ & Excess suicide $(95 \% \mathrm{Cl})$ & $P$ value \\
\hline \multicolumn{4}{|c|}{ All study countries $(n=54)$} \\
\hline \multicolumn{4}{|c|}{ All age groups: } \\
\hline Men & $1.033(1.027$ to 1.039$)$ & 5124 (4219 to 6029$)$ & $<0.001$ \\
\hline Women & 0.995 (0.987 to 1.003$)$ & $-240(-607$ to 126$)$ & 0.20 \\
\hline \multicolumn{4}{|c|}{ Aged 15-24: } \\
\hline Men & $1.058(1.035$ to 1.081$)$ & 1026 (645 to 1407$)$ & $<0.001$ \\
\hline Women & 1.017 (0.971 to 1.066$)$ & $88(-158$ to 333$)$ & 0.48 \\
\hline \multicolumn{4}{|c|}{ Aged 25-44: } \\
\hline Men & $1.041(1.023$ to 1.060$)$ & 2179 (1227 to 3130$)$ & $<0.001$ \\
\hline Women & $1.012(0.974$ to 1.054$)$ & $173(-383$ to 729$)$ & 0.54 \\
\hline \multicolumn{4}{|c|}{ Aged 45-64: } \\
\hline Men & $1.036(1.008$ to 1.065$)$ & 1980 (476 to 3484$)$ & 0.010 \\
\hline Women & 1.001 (0.974 to 1.029$)$ & $11(-416$ to 437$)$ & 0.96 \\
\hline \multicolumn{4}{|l|}{ Aged $\geq 65:$} \\
\hline Men & 0.977 (0.936 to 1.022$)$ & $-693(-2014$ to 627$)$ & 0.30 \\
\hline Women & $0.963(0.908$ to 1.025$)$ & $-462(-1215$ to 290$)$ & 0.23 \\
\hline \multicolumn{4}{|c|}{ European countries $(n=27)$} \\
\hline \multicolumn{4}{|c|}{ All age groups: } \\
\hline Men & $1.042(1.034$ to 1.051$)$ & 2937 (2400 to 3475 ) & $<0.001$ \\
\hline Women & $1.003(0.995$ to 1.010$)$ & 49 (-87 to 186$)$ & 0.48 \\
\hline \multicolumn{4}{|c|}{ Aged 15-24: } \\
\hline Men & $1.117(1.072$ to 1.166$)$ & 811 (521 to 1101$)$ & $<0.001$ \\
\hline Women & $1.106(1.028$ to 1.197$)$ & 149 (43 to 255$)$ & 0.006 \\
\hline \multicolumn{4}{|c|}{ Aged 25-44: } \\
\hline Men & $1.055(1.031$ to 1.080$)$ & 1302 (753 to 1852$)$ & $<0.001$ \\
\hline Women & 1.009 (0.967 to 1.055$)$ & $41(-160$ to 241$)$ & 0.69 \\
\hline \multicolumn{4}{|c|}{ Aged 45-64: } \\
\hline Men & $1.048(1.013$ to 1.086$)$ & 1177 (321 to 2033) & 0.007 \\
\hline Women & 1.003 (0.975 to 1.033$)$ & 19 (-164 to 203$)$ & 0.84 \\
\hline \multicolumn{4}{|l|}{ Aged $\geq 65$ : } \\
\hline Men & 1.018 (1.004 to 1.033$)$ & 246 (51 to 440$)$ & 0.013 \\
\hline Women & 0.990 (0.965 to 1.017$)$ & $-56(-206$ to 95$)$ & 0.47 \\
\hline \multicolumn{4}{|c|}{ American countries ( $n=18$ ) } \\
\hline \multicolumn{4}{|c|}{ All age groups: } \\
\hline Men & 1.064 (1.054 to 1.075$)$ & 3175 (2692 to 3658 ) & $<0.001$ \\
\hline Women & $1.023(1.011$ to 1.035$)$ & 305 (144 to 466$)$ & $<0.001$ \\
\hline \multicolumn{4}{|c|}{ Aged 15-24: } \\
\hline Men & 1.009 (0.983 to 1.036$)$ & 75 (-141 to 292$)$ & 0.50 \\
\hline Women & $1.012(0.966$ to 1.064$)$ & 30 (-87 to 146$)$ & 0.62 \\
\hline \multicolumn{4}{|c|}{ Aged 25-44: } \\
\hline Men & $1.036(1.015$ to 1.057$)$ & 656 (289 to 1023$)$ & $<0.001$ \\
\hline Women & 0.994 (0.969 to 1.020$)$ & $-28(-151$ to 94$)$ & 0.65 \\
\hline \multicolumn{4}{|c|}{ Aged 45-64: } \\
\hline Men & $1.052(1.031$ to 1.073$)$ & 850 (525 to 1174$)$ & $<0.001$ \\
\hline Women & $1.010(0.982$ to 1.040$)$ & $53(-94$ to 199$)$ & 0.48 \\
\hline
\end{tabular}


Table 1 (continued)

\begin{tabular}{|c|c|c|c|}
\hline & Rate ratio $(95 \% \mathrm{Cl})$ & Excess suicide $(95 \% \mathrm{Cl})$ & $P$ value \\
\hline \multicolumn{4}{|l|}{ Aged $\geq 65$ : } \\
\hline Men & $1.038(1.017$ to 1.060$)$ & 286 (133 to 439$)$ & $<0.001$ \\
\hline Women & $1.023(0.987$ to 1.061$)$ & $32(-19$ to 83$)$ & 0.22 \\
\hline \multicolumn{4}{|c|}{ Non-European and non-American countries $(n=9)$} \\
\hline \multicolumn{4}{|c|}{ All age groups: } \\
\hline Men & 0.974 (0.960 to 0.988 ) & $-989(-1533$ to -444$)$ & $<0.001$ \\
\hline Women & 0.963 (0.945 to 0.981$)$ & $-595(-895$ to -295$)$ & $<0.001$ \\
\hline \multicolumn{4}{|c|}{ Aged 15-24: } \\
\hline Men & $1.055(1.008$ to 1.106$)$ & 140 (21 to 258 ) & 0.021 \\
\hline Women & 0.938 (0.831 to 1.076$)$ & $-91(-279$ to 97$)$ & 0.34 \\
\hline \multicolumn{4}{|c|}{ Aged 25-44: } \\
\hline Men & $1.020(0.961$ to 1.086$)$ & $221(-464$ to 905$)$ & 0.53 \\
\hline Women & 1.034 (0.935 to 1.157$)$ & $160(-344$ to 665$)$ & 0.53 \\
\hline \multicolumn{4}{|c|}{ Aged 45-64: } \\
\hline Men & 0.997 (0.920 to 1.087$)$ & $-47(-1240$ to 1146$)$ & 0.94 \\
\hline Women & 0.985 (0.908 to 1.077$)$ & $-62(-418$ to 295$)$ & 0.73 \\
\hline \multicolumn{4}{|l|}{ Aged $\geq 65$ : } \\
\hline Men & 0.869 (0.764 to 1.009$)$ & $-1225(-2522$ to 72$)$ & 0.064 \\
\hline Women & 0.918 (0.807 to 1.065$)$ & $-439(-1174$ to 297$)$ & 0.24 \\
\hline
\end{tabular}

*As listed in figure 1. Two countries (Belize and Kuwait) had no suicides in certain sex/age groups in 2000-09 and were excluded from analyses stratified by sex and age group. Sum of age specific excess suicides was not exactly equal to all age excess suicides because age specific estimates were based on age specific time trends, which can differ from trends in all age suicide rates. 


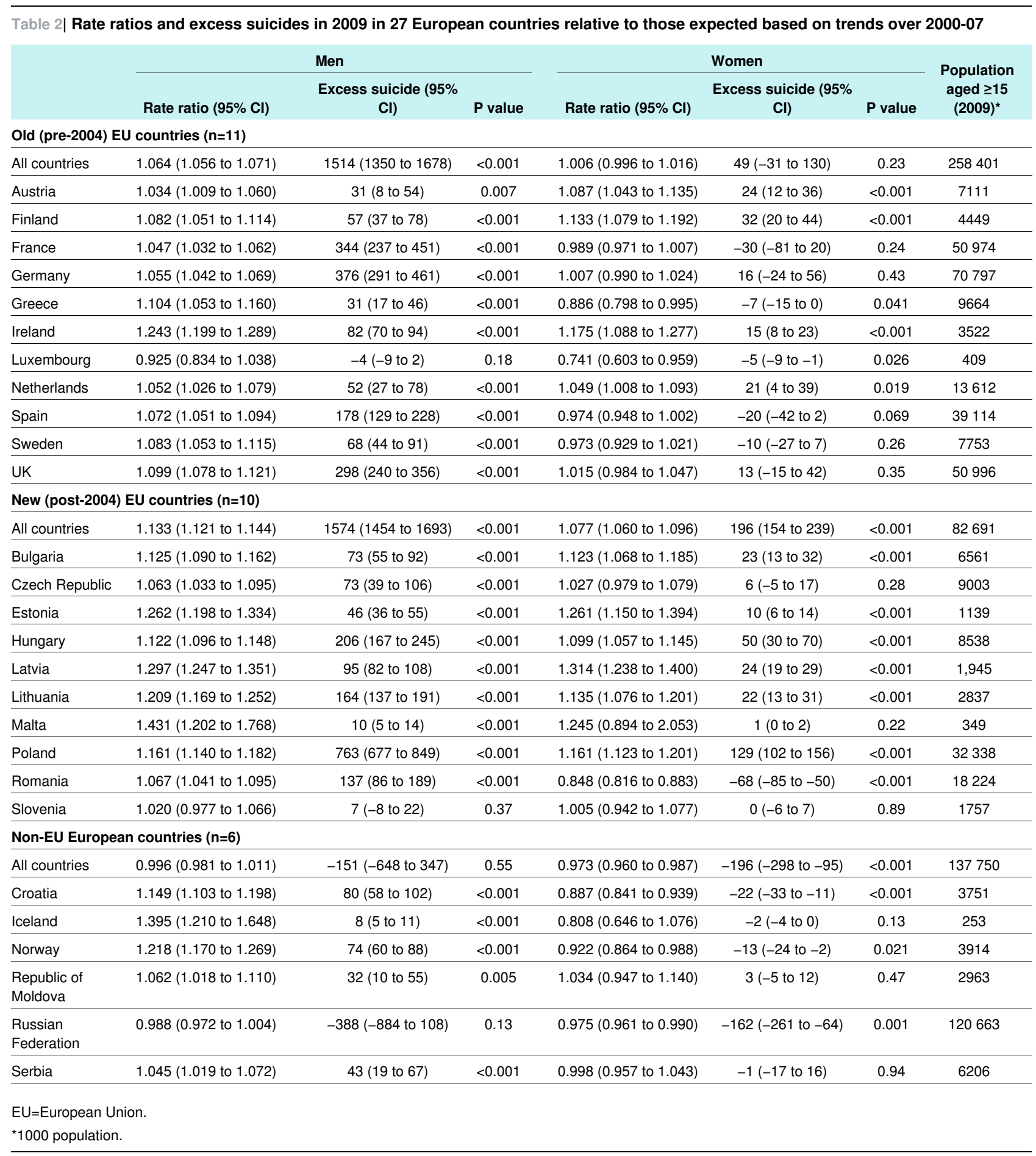


Table 3| Rate ratios and excess suicides in 2009 in 18 American countries relative to those expected based on trends over 2000-07

\begin{tabular}{|c|c|c|c|c|c|c|c|}
\hline & \multicolumn{3}{|c|}{ Men } & \multicolumn{3}{|c|}{ Women } & \multirow{2}{*}{$\begin{array}{c}\text { Population } \\
\text { aged } \geq 15 \\
(2009)^{\star}\end{array}$} \\
\hline & Rate ratio $(95 \% \mathrm{Cl})$ & Excess suicide $(95 \% \mathrm{Cl})$ & $P$ value & Rate ratio $(95 \% \mathrm{Cl})$ & $\begin{array}{l}\text { Excess suicide (95\% } \\
\mathrm{Cl})\end{array}$ & $P$ value & \\
\hline \multicolumn{8}{|c|}{ North American countries $(n=2)$} \\
\hline All countries & 1.089 (1.072 to 1.106$)$ & 2603 (2142 to 3064$)$ & $<0.001$ & $1.023(1.006$ to 1.041$)$ & 195 (51 to 339$)$ & 0.008 & 273202 \\
\hline Canada & 1.110 (1.089 to 1.132$)$ & 294 (243 to 346$)$ & $<0.001$ & $1.016(0.987$ to 1.047$)$ & $14(-12$ to 40$)$ & 0.29 & 28078 \\
\hline United States & $1.087(1.068$ to 1.106$)$ & 2309 (1850 to 2767$)$ & $<0.001$ & $1.024(1.005$ to 1.044$)$ & 181 (39 to 323 ) & 0.012 & 245124 \\
\hline \multicolumn{8}{|c|}{ Caribbean and Central American countries $(n=9)$} \\
\hline All countries & $1.064(1.052$ to 1.076$)$ & 390 (319 to 461$)$ & $<0.001$ & $1.254(1.219$ to 1.290$)$ & 326 (290 to 363$)$ & $<0.001$ & 110439 \\
\hline Aruba & $0.578(0.427$ to 0.891$)$ & $-3(-5$ to 0$)$ & 0.018 & $-\dagger$ & $-2(-3$ to 0$)$ & 0.005 & 86 \\
\hline Belize & 1.770 (1.390 to 2.437$)$ & 5 (3 to 6$)$ & $<0.001$ & $4.316(2.718$ to 10.470$)$ & $3(3$ to 4$)$ & $<0.001$ & 196 \\
\hline Costa Rica & $0.827(0.781$ to 0.879$)$ & $-49(-66$ to -32$)$ & $<0.001$ & $0.703(0.615$ to 0.819$)$ & $-16(-24$ to -9$)$ & $<0.001$ & 3423 \\
\hline Cuba & 1.168 (1.138 to 1.200$)$ & 164 (138 to 190$)$ & $<0.001$ & 1.506 (1.445 to 1.572$)$ & $112(103$ to 121$)$ & $<0.001$ & 9268 \\
\hline$\underline{\text { El Salvador }}$ & $1.085(1.026$ to 1.151$)$ & $31(10$ to 51$)$ & 0.004 & 1.141 (1.071 to 1.222$)$ & 13 (7 to 19$)$ & $<0.001$ & 4145 \\
\hline Guatemala & 1.271 (1.195 to 1.356$)$ & 76 (58 to 94$)$ & $<0.001$ & 1.908 (1.698 to 2.178$)$ & 64 (55 to 72$)$ & $<0.001$ & 8163 \\
\hline Mexico & 1.054 (1.039 to 1.070$)$ & 203 (149 to 258$)$ & $<0.001$ & $1.157(1.111$ to 1.207$)$ & 120 (89 to 152$)$ & $<0.001$ & 79000 \\
\hline Nicaragua & $0.960(0.913$ to 1.013$)$ & $-11(-26$ to 4$)$ & 0.14 & $1.396(1.269$ to 1.552$)$ & 24 (18 to 30$)$ & $<0.001$ & 3709 \\
\hline Panama & $0.852(0.799$ to 0.914$)$ & $-25(-37$ to -14$)$ & $<0.001$ & $1.442(1.256$ to 1.693$)$ & $8(6$ to 11$)$ & $<0.001$ & 2449 \\
\hline \multicolumn{8}{|c|}{ South American countries $(n=7)$} \\
\hline All countries & 1.013 (1.004 to 1.022$)$ & 182 (59 to 306$)$ & 0.004 & $0.942(0.927$ to 0.958$)$ & $-216(-279$ to -154$)$ & $<0.001$ & 233138 \\
\hline Argentina & $0.977(0.950$ to 1.006$)$ & $-54(-121$ to 13$)$ & $<0.001$ & 0.944 (0.905 to 0.987 ) & $-33(-59$ to -7$)$ & 0.011 & 29988 \\
\hline Brazil & $1.006(0.995$ to 1.017$)$ & $43(-37$ to 124$)$ & 0.29 & 0.928 (0.908 to 0.948 ) & $-142(-184$ to -99$)$ & $<0.001$ & 143236 \\
\hline Chile & 1.109 (1.083 to 1.137$)$ & 168 (131 to 205$)$ & $<0.001$ & $1.129(1.073$ to 1.191$)$ & 47 (28 to 66$)$ & $<0.001$ & 13124 \\
\hline Colombia & $1.102(1.078$ to 1.126$)$ & 162 (127 to 196$)$ & $<0.001$ & 1.037 (0.981 to 1.099$)$ & $15(-8$ to 38$)$ & 0.21 & 32352 \\
\hline Ecuador & $0.830(0.794$ to 0.870$)$ & $-142(-180$ to -104$)$ & $<0.001$ & 0.709 (0.666 to 0.759$)$ & $-92(-113$ to -72$)$ & $<0.001$ & 9880 \\
\hline Paraguay & 1.041 (0.968 to 1.127$)$ & $8(-7$ to 23$)$ & 0.29 & 0.855 ( 0.760 to 0.977 ) & $-11(-21$ to -2$)$ & 0.023 & 4188 \\
\hline Suriname & $0.972(0.886$ to 1.077$)$ & $-3(-13$ to 7$)$ & 0.57 & 0.986 (0.827 to 1.223$)$ & $0(-6$ to 5$)$ & 0.89 & 370 \\
\hline
\end{tabular}

${ }^{*} 1000$ population.

†Zero suicides. 
Table 4| Rate ratios and excess suicides in 2009 in East Asian and African countries relative to those expected based on trends over 2000-07

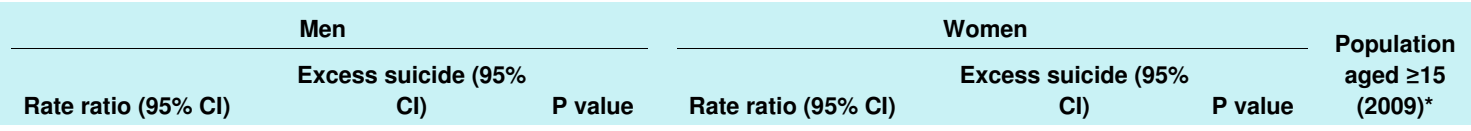

East Asian countries $(n=4)$

Cl) P value Rate ratio $(95 \% \mathrm{Cl})$

\begin{tabular}{|c|c|c|c|c|c|c|c|}
\hline All countries & $0.970(0.955$ to 0.986$)$ & $-1009(-1548$ to -470$)$ & $<0.001$ & $0.956(0.938$ to 0.976$)$ & $-658(-957$ to -360$)$ & $<0.001$ & 159424 \\
\hline Hong Kong SAR & $0.866(0.825$ to 0.913$)$ & $-96(-133$ to -60$)$ & $<0.001$ & $0.957(0.912$ to 1.005$)$ & $-18(-38$ to 2$)$ & 0.079 & 6130 \\
\hline Japan & $0.987(0.971$ to 1.004$)$ & $-283(-663$ to 96$)$ & 0.14 & $0.967(0.945$ to 0.990$)$ & $-289(-492$ to -86$)$ & 0.005 & 108955 \\
\hline Republic of Korea & 0.940 (0.907 to 0.975$)$ & $-632(-1012$ to -251$)$ & 0.001 & 0.944 (0.910 to 0.981$)$ & $-320(-538$ to -102$)$ & 0.004 & 41273 \\
\hline Singapore & $1.011(0.954$ to 1.075$)$ & $3(-11$ to 16$)$ & 0.71 & $0.781(0.728$ to 0.844$)$ & $-31(-42$ to -20$)$ & $<0.001$ & 3066 \\
\hline
\end{tabular}

Other Asian countries $(n=4)$

\begin{tabular}{llcccccc}
\hline All countries & $1.003(0.983$ to 1.024$)$ & $10(-67$ to 88$)$ & 0.79 & $1.081(1.046$ to 1.119$)$ & $68(40$ to 95$)$ & $<0.001$ & 23040 \\
\hline Israel & $1.120(1.072$ to 1.172$)$ & $33(21$ to 45$)$ & $<0.001$ & $1.059(0.971$ to 1.163$)$ & $5(-3$ to 13$)$ & 0.20 & 5399 \\
\hline Kazakhstan & $0.978(0.955$ to 1.002$)$ & $-69(-144$ to 5$)$ & 0.068 & $1.081(1.041$ to 1.125$)$ & $52(27$ to 77$)$ & $<0.001$ & 12064 \\
\hline Kuwait & $0.899(0.772$ to 1.078$)$ & $-4(-12$ to 3$)$ & 0.23 & $1.430(1.128$ to 1.953$)$ & $6(2$ to 10$)$ & 0.002 & 1955 \\
\hline Kyrgyzstan & $1.170(1.117$ to 1.229$)$ & $52(37$ to 66$)$ & $<0.001$ & $1.046(0.943$ to 1.175$)$ & $4(-6$ to 14$)$ & 0.41 & 3622 \\
\hline African countries $(\mathbf{n}=1)$ & & & & & & \\
\hline Mauritius & $1.120(1.027$ to 1.230$)$ & $10(2$ to 17$)$ & 0.009 & $0.842(0.734$ to 0.989$)$ & $-4(-7$ to 0$)$ & 0.037 & 966
\end{tabular}

*1000 population. 
Table 5| Correlation between unemployment rate (\%) point changes between 2007 and 2009 and suicide rate ratios in 2009 relative to expected from 2000-07 trend in 50 countries and stratified by unemployment level before crisis in 2007

$$
\text { No of countries Spearman's } r_{s}(95 \% \mathrm{Cl}) \quad \mathrm{P} \text { value }
$$

All countries

\begin{tabular}{llll}
\hline Men & 50 & $0.25(-0.03$ to 0.50$)$ & 0.075 \\
\hline Women & 50 & $0.10(-0.18$ to 0.37$)$ & 0.49 \\
\hline
\end{tabular}

Countries with low unemployment level $(<6.2 \%)$ before crisis

\begin{tabular}{llcc}
\hline Men & 25 & $0.48(0.10$ to 0.73$)$ & 0.016 \\
\hline Women & 25 & $0.13(-0.28$ to 0.50$)$ & 0.55
\end{tabular}

Countries with high unemployment level $(\geq 6.2 \%)$ before crisis

\begin{tabular}{llll}
\hline Men & 25 & $0.31(-0.10$ to 0.63$)$ & 0.13 \\
\hline Women & 25 & $0.20(-0.21$ to 0.55$)$ & 0.34 \\
\hline
\end{tabular}




\section{Figures}

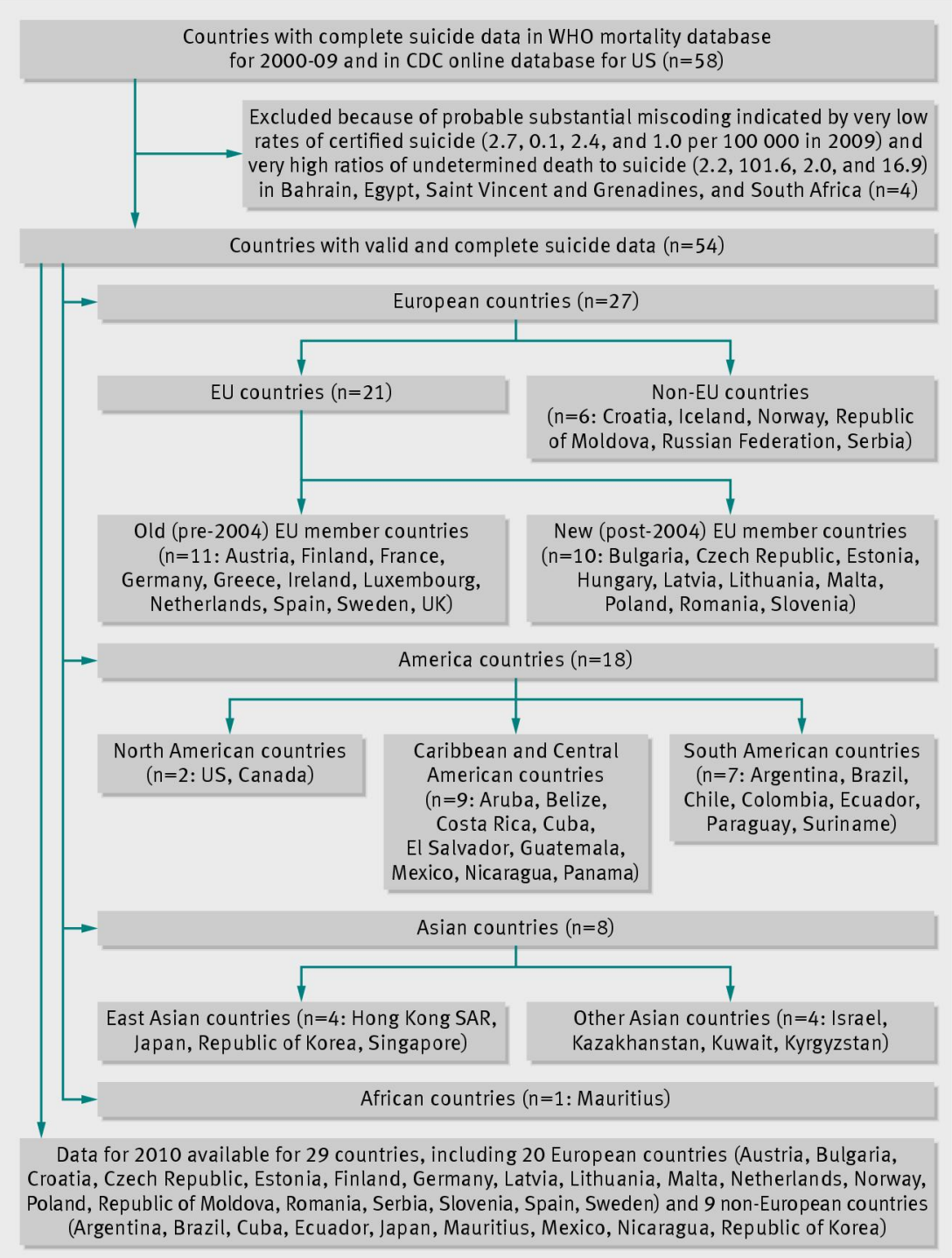

Fig 1 Countries included in study $(n=54)$. "Nineteen countries (Argentina, Aruba, Belize, Brazil, Canada, Chile, Colombia, Costa Rica, Cuba, Ecuador, El Salvador, France, Guatemala, Kuwait, Mexico, Nicaragua, Panama, Paraguay, Suriname) had incomplete population data for study period in WHO mortality database; their population data were obtained from United Nations population database ${ }^{21}$ 


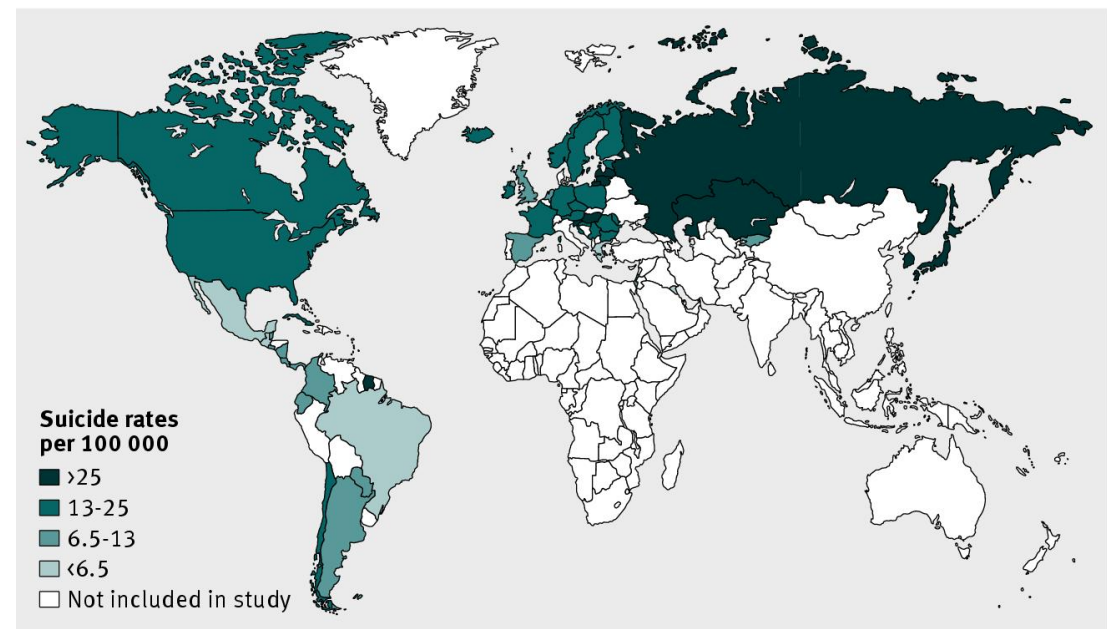

Fig 2 Map of study countries and their suicide rates in 2009

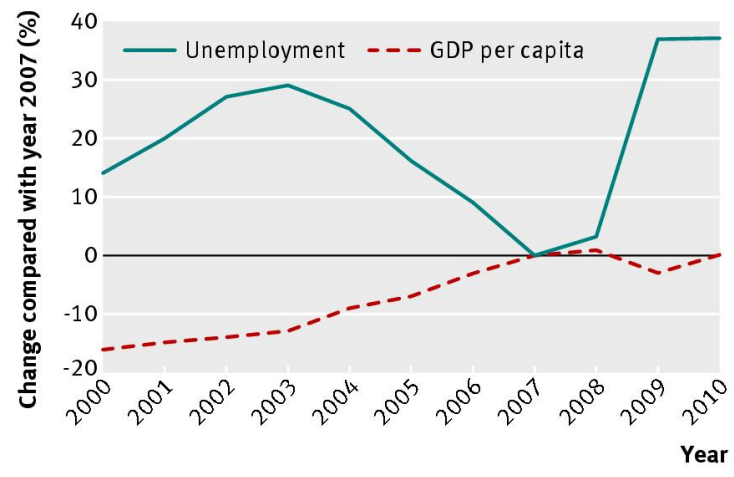

Fig 3 Changes in unemployment rates and gross domestic product (GDP) per capita in 54 study countries 

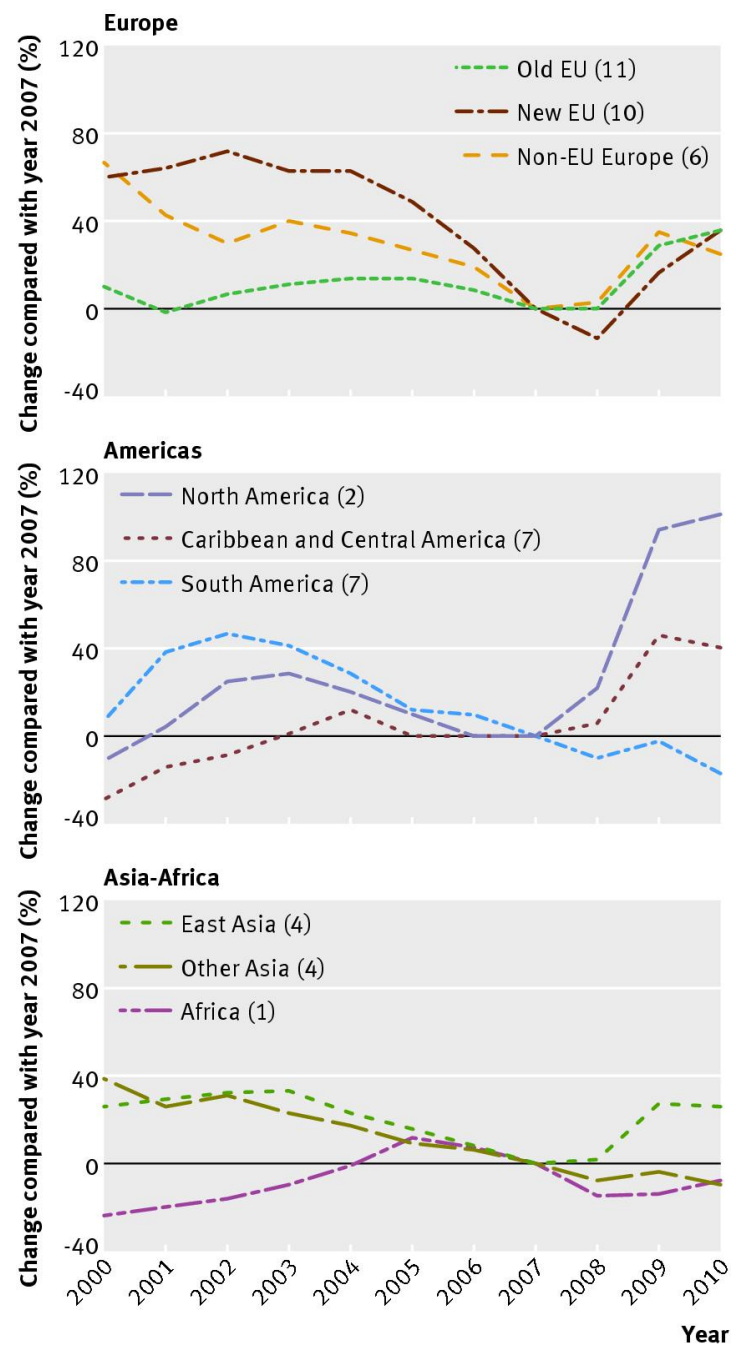

Fig 4 Changes in unemployment rates in nine different regions (number of countries included in region), 2000-10. Data weighted by countries' population sizes in 2009. Unemployment data for two American countries (Aruba and Guatemala) were unavailable 